\title{
ANALISIS KUALITAS AIR DALAM PENENTUAN LOKASI BUDIDAYA RUMPUT LAUT (Eucheuma cottonii) DI KAWASAN TELUK PAREPARE
}

\author{
(Analysis Of Water Quality In Determination Of (Eucheuma cottonii) \\ Seaweed Cultivation Location In Parepare Bay Region) \\ Damis ${ }^{1)}$ dan Muhammad Saenong ${ }^{2)}$ \\ 1) Universitas Muhammadiyah Sidenreng Rappang \\ 2) Program Studi Budidaya Perairan FPIK UMI Makassar \\ Korespondensi:damis.jumardi@gmail.com
}

Diterima: tanggal 15 Juli 2020; Disetujui 30 Agustus 2020

\begin{abstract}
This study aims to determine land suitability for seaweed cultivation in the Parepare Bay Region, assessing the feasibility of developing seaweed cultivation; identify factors that influence the development of seaweed cultivation; Conformity evaluation conducted in this study is the actual suitability or suitability of seaweed cultivation land, where the resulting land suitability class is only based on available data, not considering social, economic, financial, and other aspects. The research method used is a direct survey at the research location. The results of the land suitability analysis are based on the suitability matrix: spatial data analysis using the Geogerafis Information System method, to determine the suitability of seaweed cultivation land. The results showed that the area of land suitability for seaweed cultivation based on the land suitability map was appropriate $(S) \pm 578.57 \mathrm{ha}$ and not suitable $(N) \pm 759.68 \mathrm{ha}$
\end{abstract}

Keywords: Analysis; Water Quality; Eucheuma cottonii; Seaweed Cultivation Parepare Bay Region

\begin{abstract}
ABSTRAK
Penelitian ini bertujuan untuk menentukan kesesuain lahan untuk budidaya rumput laut di Wilayah Teluk Parepare, menilai kelayakan pengembangan budidaya rumput laut; mengidentifikasi faktor-faktor yang mempengaruhi pengembangan budidaya rumput laut; evaluasi kesesuaian yang dilakukan didalam studi ini merupakan kesesuaian aktual atau kesesuaian lahan budidaya rumput laut, di mana kelas kesesuaian lahan yang dihasilkan hanya didasarkan pada data yang tersedia, belum mempertimbangkan aspek sosial, ekonomi, finansial, dan aspek lainya. Metode penelitian yang digunakan yakni survey langsung di lokasi penelitian. Hasil analisis kesesuaian lahan berdasarkan matriks kesesuaian: analisis data spasial dengan metode Sistem Informasi Geogerafis, untuk menetukan kesesuaian lahan budidaya rumput laut. Hasil penelitian menunjukkan bahwa luas kesesuain lahan untuk budidaya rumput laut berdasarkan peta kesesuaian lahan adalah sesuai $(\mathrm{S}) \pm 578,57$ ha dan tidak sesuai $(\mathrm{N}) \pm 759,68$ ha
\end{abstract}

Kata Kunci: Analisis; kualitas air; rumput laut; Euchea cottonii; kawasan teluk Parepare 


\section{PENDAHULUAN}

Melihat kenyataan ini orientasi pembangunan perikanan ke depan harus lebih diarahkan kepada perikanan budidaya yang mengedepankan aspek keberlanjutan. Statistik produksi budidaya Indonesia menempati urutan ke-5 setelah China, India, Jepang dan Philipina dengan volume produksi $2 \%$ dari produksi budidaya dunia. Negara penghasil budidaya laut masih didominasi oleh Cina dengan produksi mencapai 32,44 juta ton atau menguasai $70 \%$ produksi perikanan budidaya dunia. (FAO dalam Fatahuddin, 2016).

Pengembangan budidaya rumput laut memerlukan sebuah desain perencanaan yang menjamin pengembangan usaha rumput laut, memberikan gambaran dan arah yang jelas, komprehensif, multi tahun (multi years) serta memperhatikan aspek bioekologi, teknis, sosial budaya dan ekonomi dengan melibatkan kepentingan semua stakeholders. Hal ini perlu dilakukan untuk meminimalisasi kerusakan sumberdaya kelautan dan perikanan serta meningkatkan usaha pemanfaatan dan pengembangan rumput laut yang berkelanjutan dalam jangka waktu yang panjang, oleh karena itu diperlukan adanya perencanaan pengembangan budidaya rumput laut yang sesuai peruntukan bagi pengelolaan masingmasing kegiatan dengan mempertimbangkan karakteristik, lingkungan serta menjaga kelestarian sumberdaya alam dan lingkungan hidup secara bersama-sama. Kondisi perairan Teluk Parepare sangat memungkinkan untuk pengembangan budidaya rumput laut. Pengembangan budidaya rumput laut perlu diarahkan fungsinya, yaitu untuk mewujudkan keselarasan dan keserasian suatu pembangunan dengan pembangunan lainnya, prasarana dan lingkungannya, serta menjaga keselamatan pembangunan, bangunan dan lingkungannya.

Berdasarkan uraian tersebut di atas maka hal penting yang diperlukan adalah melaksanakan kegiatan potensi sumberdaya alam pesisir dan lautan yang mendukung kegiatan budidaya rumput laut. Melalui proses pengelolaan pesisir secara menyeluruh yang mencakup penyusunan zonasi dan arahan pengembangan kegiatan budidaya rumput laut berdasarkan 
dengan kesesuaian lahannya dalam tulis menulis untuk pencatatan data, Peta rencana tata ruang, sehingga rupa bumi untuk penentuan titik lokasi diharapkan dapat terlaksana penelitian, Data Citra Satelit Spot 4 sebagai pembangunan Wilayah Pesisir yang menguntungkan dan berkelanjutan, dengan memperhatikan fungsi preservasi, konservasi dan fungsi pemanfaatannya (Asmidar, 2011). Penelitian ini bertujuan untuk menganalisis kesesuaian lahan budidaya rumput laut, di Wilayah Pesisir Teluk Parepare.

\section{MATERI DAN METODE}

Penelitian ini dilakasankan selama dua bulan, yakni pada bulan Oktober 2017 sampai Desember 2017. Lokasi penelitian di sekitar Wilayah Pesisir Teluk Parepare. Alat dan bahan yang digunakan dalam penelitian ini yaitu GPS untuk penentuan posisi stasiun pengamatan, Thermometer untuk mengukur suhu perairan, $\mathrm{pH}$ meter untuk mengukur keasaman, Handrefraktometer untuk mengukur salinitas perairan, Kompas untuk penentuan arah arus, Secchi disk untuk mengukur tingkat kecerahan, Layangan arus untuk menetukan arah dan kecepatan arus, Tiang Skala untuk mengukur kedalaman dan pasang surut, Perahu untuk sebagai alat transportasi, Perangkat computer untuk pengolahan analisis data, software Arcgis untuk olah data SIG, Alat data primer (Damis, 2018)

Tahapan ini dimulai dengan studi pendahuluan yang meliputi studi literatur/pustaka dan diskusi yang berhubungan dengan ruang lingkup penelitian, malakukan survei awal di lapangan untuk mengetahui kondisi umum di lapangan, disamping itu juga di lakukan pengumpulan data sekunder yang berhubungan dengan hal-hal yang akan diteliti, sehingga berdasarkan hasil survei dan data sekunder ini dapat memudahkan dalam penentuan metode dan teknik pengambilan dan analisis data.

Prosedur penelitian ini meliputi kegiatan persiapan/observasi awal di lapangan, penentuan titik sampel atau pemilihan stasiun pengamatan, pengambilan data di lapangan, pengambilan sampel kemudian pengamatan di laboratorium, serta pembuatan laporan.

\section{a. Tahapan Penentuan Stasiun}

Stasiun pengamatan ditentukan dengan mempertimbangkan wilayah penelitian berdasarkan hasil survei awal dan karakteristik kondisi perairan 
dengan menggunakan Global dengan pengelolaan kawasan pesisir di Positioning System (GPS), hal ini Kecamatan Suppa Kabupaten Pinrang, dilakukan untuk mempermudah dalam yaitu dari unsur birokrasi, akademisi, penentuan luasan fisik cakupan baik pelaku usaha, dan lembaga swadaya tiap stasiun maupun luasan area masyarakat (LSM) yang peduli pada pengamatan secara keseluruhan.

\section{b. Pengambilan Data Lapangan}

Data-data yang akan dikumpulkan dalam penelitian ini terdiri dari data primer dan data sekunder. Data primer meliputi: data fisik-geografi kawasan pesisir diperoleh melalui observasi lapangan pada wilayah penelitian dan melalui hasil wawancara semi terstruktur dengan pengguna (stakeholders) yang terkait di wilayah tersebut, dan data sekunder yang diperoleh dari instansi terkait.

\section{c. Teknik Penentuan Responden}

Teknik pengambilan responden dalam rangka menggali informasi/ pendapat stakeholders adalah metode expert judgement (Pendapat Pakar). Pakar ditentukan secara purposive sampling. Pakar responden berjumlah 12 orang, yang merupakan key persons (tokoh kunci) yang mewakili kelompok- kelompok stakeholders yang diperoleh pada saat identifikasi stakeholders. Kelompok stakeholders ini meliputi setiap unsur yang terkait pengelolaan pesisir.

\section{d. Parameter Kualitas Air}

Pengamatan kulitas air dilakukan di kawasan perairan yang secara eksisting terdapat kegiatan rumput laut, kawasan mangrove, dan kawasan perairan pantai. Pengamatan kualitas air bertujuan untuk menentukan present status kondisi perairan pesisir yang terkait dengan kelayakan lingkungan untuk budidaya rumput laut. Pengamatan dilakukan sekali satu bulan pada saat terjadi pasang tertinggi dan surut terendah, dengan masing-masing pengamatan pada bulan Oktober sampai Desembar 2017.

Prosedur pengolahan penelitian ini meliputi penentuan titik sampel atau pemilihan stasiun pengamatan, pengambilan data di lapangan, pengambilan sampel kemudian pengamatan di laboratorium, serta pembuatan laporan penelitian

Hal yang perlu dilakukan pada tahap analisis spasial untuk kesesuaian rumput laut, yaitu (i) mengidentifikasi 
kondisi substrat dasar perairan dari budidaya rumput laut perlu kenampakan citra satelit spot 4; tahapan memperhatikan faktor yang ini dilakukan diawal kegiatan dengan mempengaruhi pertumbuhan rumput maksud untuk mendapatkan informasi laut baik faktor lingkungan (Syamsiah. awal mengenai sebaran informasi 2007). biologi maupun fisik, Adapun territorial dan pesisir laut yang Kriteria yang dikerkomondasikan untuk mungkin dijumpai di lokasi dengan kegiatan budidaya rumput laut di teknik penginderaan jauh, dan (ii) sajikan pada Tabel 1. Metode indeks melakukan interpretasi citra dengan overlay model adalah setiap coverage berbagai metode analisis dengan memiliki urutan kepentingan paling maksud untuk mendapatkan pola besar diberikan nilai lebih tinggi sebaran dari hasil identifikasi sehingga ketingkat lebih kecil (Benham dan diperoleh kenampakan yang sesuai Carter, 1994; Subandar, 1998; Rauf, dengan kondisi eksisting lokasi 2012). Model matematis disajikan penelitian. Agar hasil yang dicapai sebagai berikut:

dapat dipertanggungjawabkan, maka hasil interpretasi tersebut diperkuat dengan melakukan ground check point terhadap lokasi pada wilayah yang menjadi fokus pengamatan. Untuk memenuhi kebutuhan data dan informasi mengenai kondisi fisik permukaan bumi tersebut, maka teknologi penginderaan jauh merupakan salah satu alternatif teknologi yang dapat dimanfaatkan mengingat kemampuannya dalam menghimpun informasi fisik kebumian secara tepat, cepat dan terkini (up-to date) dengan biaya yang relatif lebih mudah terjangkau. Zonasi kesesuaian

$$
S=\frac{\sum_{i}^{n} S i j . W i}{\sum_{i}^{n} W i}
$$

Keterangan:

S : Indeks terbobot pada area objek atau area terpilih

Sij : Skor pada kelas ke-j dari peta ke-i

$\mathrm{W}_{\mathrm{i}} \quad$ : Bobot pada input peta ke-i n : Jumlah Peta

\section{HASIL DAN PEMBAHASAN}

Hasil analisis kesesuaian lahan budidaya rumput laut, dengan menggunakan hasil overlay dari semua parameter di antaranya gelombang, arus, kedalaman, kecerahan salinitas, suhu, pH, DO, nitrat, dan fosfat merupakan gabungan data spasial dan 
atribut dari suatu wilayah, sebagaimana disajikan pada tabel berikut:

Tabel 1. Kualitas air selama pemeliharaan

\begin{tabular}{|c|c|c|c|}
\hline $\begin{array}{c}\text { Lokasi } \\
\text { (Kordinat) }\end{array}$ & Kesesuaian Rumput laut & Luas & Persentase $(\%)$ \\
\hline \multirow{3}{*}{ Wilayah pesisir } & Sesuai & $\pm 578,57$ & 43,23 \\
\hline & Tidak sesuai & $\pm 759,68$ & 56,77 \\
\hline & Luas kawasan & $\pm 1.388,25$ & 100 \\
\hline
\end{tabular}

Hasil analisis menunjukan bahwa sesuai perubahan kondisi lingkungan di perairan Kecamatan Suppa yang yang terjadi dilokasi penelitian. mencakup Wilayah pesisir merupakan beberapa hal yang menjadi lokasi dengan kesesuaian lokasi kekhawatiran penulis yakni beberapa budidaya rumput laut sesuai $\pm 578,57$ bagian ruang daratan disekitar lokasi ha dan tidak sesuai $\pm 759,68$ ha. perairan akan dikonversi beberapa Hasil analisis menunjukan bahwa peruntukan seperti areal permukiman, di perairan Kecamatan Suppa buangan limbah air balas dari proses mencakup Wilayah pesisir merupakan pendinginan pembangkit listrik sangat lokasi dengan kesesuaian lokasi besar pengaruhnya jika buangan limbah budidaya rumput laut sesuai 578,57 ha tersebut tidak melalui tretmen terlebih dan tidak sesuai 759,68 ha. Kondisi dahulu dibuang ke laut. Untuk melihat kualitas air yang menjadi indicator peta sebaran sesuia dan tidak sesuai dalam penentuan kesesuaian lokasi untuk budidaya rumput laut dapat budidaya rumput laut dapat berubah dilihat pada Gambar 1.

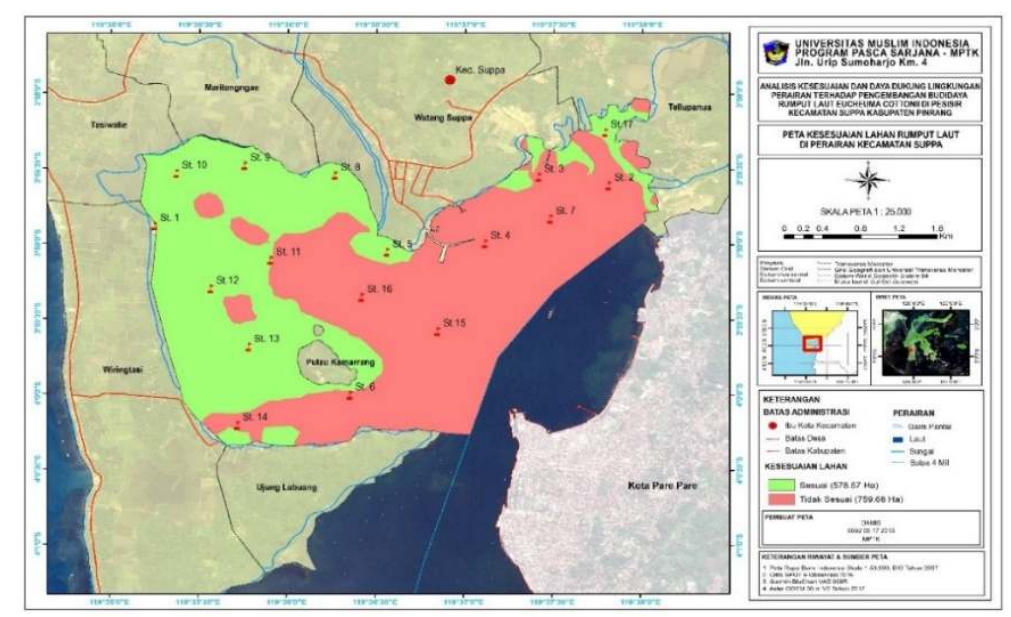

Gambar 1. Peta kesesuaian lahan budidaya rumput laut di kawasan Teluk Parepare 
Oksigen sangat dibutuhkan untuk tumbuh kembang rumput laut dalam mendukung proses metabolismenya. Oksigen merupakan dua macam gas yang memiliki arti penting dalam metabolisme. Oksigen dalam air berasal dari udara (melalui difusi) dan hasil sampingan fotosintesa tumbuhan akuatik (rumput laut). Kelarutan oksigen dalam air dipengaruhi oleh suhu air, ketinggian lokasi (latitude), salinitas, dan tekanan udara. Penambahan tekanan udara serta peningkatan suhu air dan salinitas, menyebabkan kelarutan oksigen rendah dan begitu pula sebaliknya (Wahyuningrum, 2001). Dari hasil pengukuran oksigen terlarut (DO) di titik pengamatan sangat mendukung perkembangan rumput laut. Semuanya batas angka $4 \mathrm{mg} / \mathrm{l}$ yang merupakan batas minimal untuk kriteria nilai DO yang sangat sesuai. Hasil pengamatan di setiap stasiun berkisar antara 5,79 $6,12 \mathrm{mg} / \mathrm{l}$.

Suhu suatu perairan dipengaruhi oleh radiasi matahari, posisi matahari, letak geografis, musim, kondisi awan, serta proses interaksi antara air dan udara, penguapan, dan hembusan angin
(Dahuri et al. 2004 dalam Nirmala $d k k$, 2014). Menurut Effendi, (2003), perubahan suhu berpengaruh terhadap proses fisika, kimia, dan biologi badan air. Rata-rata nilai suhu di perairan Desa Kamelanta dan Pulau Panjang sangat sesuai yang berkisar antara $28,55-28,79$ 0C. Suhu memiliki peranan penting dalam proses tumbuh rumput laut.

Menurut Neish (2003) suhu air yang sesuai dengan kebutuhan hidup rumput laut Kappaphycus alvarezii adalah berkisar pada 28-320C. Kenaikan temperatur yang tinggi akan mengakibatkan thallus rumput laut menjadi pucat kekuningan dan tidak sehat, rumput laut dapat tumbuh dengan baik pada kisaran suhu $26-32$ oC (DKP, 2006)

\section{KESIMPULAN}

Berdasarkan hasil penelitian yang telah dilakukan di Wilayah Pesisir Teluk Parepare maka dapat disimpulkan sebagi berikut : Hasil analisis spasial kawasan Wilayah Teluk Parepare memiliki potensi kesesuaian lahan yang sesuia untuk budidaya rumput laut $\pm 578,57$ ha, dan yang tidak sesuai $\pm 759,68$ ha. 


\section{SARAN}

Perlu dilakukan penelitian lanjutan terhadap jarak antara budidaya rumput laut dengan budidaya ikan sistem karamba jaring apung yang saling mendukung agar tidak terjadi tumpang tindih pemanfaatan. Perlu dilakukan penelitian lebih lanjut mengenai jumlah investasi dalam melakukan budidaya rumput laut di Wilayah Pesisir Teluk Parepare

\section{UCAPAN TERIMA KASIH}

Tulisan ini merupakan bagian dari penelitian tesis, oleh karena itu penulis mengucapkan terima kasih kepada seluruh Dosen dan Staf Fakultas Sains dan Teknologi Universitas Muhammadiyah Sidenreng Rappang serta Dosen dan Staf Fakultas Perikanan dan Ilmu Kelautan Universitas Muslim Indonesia .

\section{DAFTAR PUSTAKA}

Asmidar, 2011. Penilaian Evaluasi Kesesuaian Pemanfaatan Wilayah Pesisir Puntondo Kabupaten Takalar untuk Penegmbangan Budidaya Laut Berkelanjutan. Tesis Program Pascasarjana. Universitas Hasanuddin. Makassar.

Damis, 2018. Analisis Kesesuaian Dan Daya Dukung Lingkungan Perairan Terhadap Pengembangan Budidaya Rumput
Laut Eucheuma cottonii Di Pesisir Kecamatan Suppa Kabupaten Pinrang, Tesis Program Pascasarjana. Universitas Muslim Indonesia. Makassar.

Departemen Kelautan dan Perikanan. 2006.Petunjuk Teknis Budidaya Rumput Laut Eucheuma spp. Jakarta

Effendi H. 2003. Telaah kualitas air bagi pengelolaan sumber daya dan lingkungan perairan. Kanisius. Yogyakarta

Fatahuddin, 2016. Analisis Kesesuaian dan daya Dukung Perairan Rumput Laut di Pulau Saugi Kecamatan Liukang Tupabbiring Utara Kabupaten Pangkep, Tesis Program Pascasarjana. Universitas Muslim Indonesia. Makassar.

Nirmala K, Ratnasari A dan Budiman S.2014. Penentuan kesesuaian lokasi budidaya rumput laut di perairan Teluk Gerupuk - Nusa Tenggara Barat menggunakan penginderaan jauh dan SIG. Jurnal Akuakultur Indonesia 13 (1), 73-82 hal.

Neish I. 2003. The ABC of Eucheuma Seaplant Production : Agronomy, Biology and Crop-handling of Betaphycus, Eucheuma and Kappaphycus the Gelatinae, Spinosum and Cottonii of Commerce. Monograph 1-0703, SuriaLink Seaplants

Rauf, A., 2012. Carrying Capacity Basis pengelolaan Terpadu Pulau-Pulau Kecil, Pijar Press

Syamsiah. 2007. Studi Fisika-Kimia Oseanografi Perairan Tonyaman Kabupaten Polewali Mandar Untuk kesesuaian Lahan Budidaya Rumput Laut 
Kappaphycus alvarezii. Skripsi. Fakultas Ilmu Kelautan dan Perikanan Universitas Hasanuddin. Makassar.

Wahyuningrum PI. 2001. Studi evaluasi kesesuaian wilayah perairan teluk lampung untuk budidaya rumput laut Eucheuma dengan pemanfaatan penginderaan jauh dan system informasi geografi (SIG) [Skripsi]. Bogor: Institut Pertanian Bogor 